\title{
NUMERICAL SIMULATION OF HEAT TRANSPORT FROM THE ELECTRIC ARC FURNACE TO THE HEAT RECOVERY SYSTEM
}

The paper presents a numerical model of heat transport from melting charge of the electric arc furnace designed for ferroalloy production, into a cooled roof of the electric arc furnace from which waste heat is led to the heating system of a company. The model considers the influence of an asymmetric flue gas removal and geometry of electrode arrangement. The model was developed implementing CFD - the finite volume method in ANSYS - Fluent program code. Outputs of the simulation model served as a basis for dimensioning heat exchanger circuits designed for waste heat recovery to provide a company heating.

Keywords: Numerical model of heat transport, electric arc furnace, waste heat recovery, ferroalloys.

\section{Introduction}

Energy supply, energy price development together with legislative measures concerning ecology are factors which expressly encourage to pursue such technical solutions which lead to savings of waste low- and medium potential heat. This source of heat energy can advantageously be recovered in suitable facilities and used as secondary energy sources particularly in those technologies which produce it.

Secondary energy sources generally occur as a consequence of fuel and energy consumption in technological processes, in which they are not used anymore because their parameters do not fit the original technology. However, they can be an energy source for other equipment in which they can completely or partly substitute either fuel or energy.

One way of reducing costs of heat energy is its recovery from waste heat through heat exchangers of various constructions which depend on a given application.

\section{Determining the parameters of working medium in electric arc furnaces (EAF)}

The processes of ferroalloy production are reduction processes during which the main element is reduced by a reductant from its oxide to the metallic state. Together with the present iron it then forms alloy - ferroalloy [1]. Reduction processes take place at high temperatures and the required heat is supplied in the form of electric energy in the electric arc furnace (Figs. 1 and 2).

As can be seen from Sankey diagram (Fig. 3), technological processes of ferroalloy production in electric arc furnaces (EAF) show a massive flow of waste heat [2] and are potentially usable as secondary energy sources.

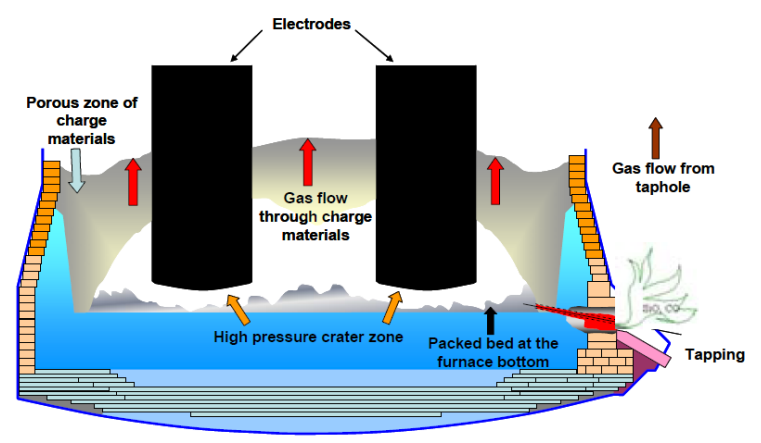

Fig. 1 Schematic of submerged arc furnace used for ferrosilicon production [1]

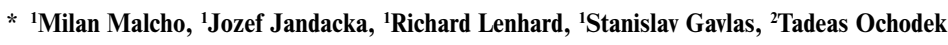

${ }^{1}$ Department of Power Engineering, Faculty of Mechanical Engineering, University of Zilina, Slovakia

${ }^{2}$ Energy Research Center, VSB - Technical University of Ostrava, Ostrava - Poruba, Czech Republic

E-mail: milan.malcho@fstroj.uniza.sk
} 


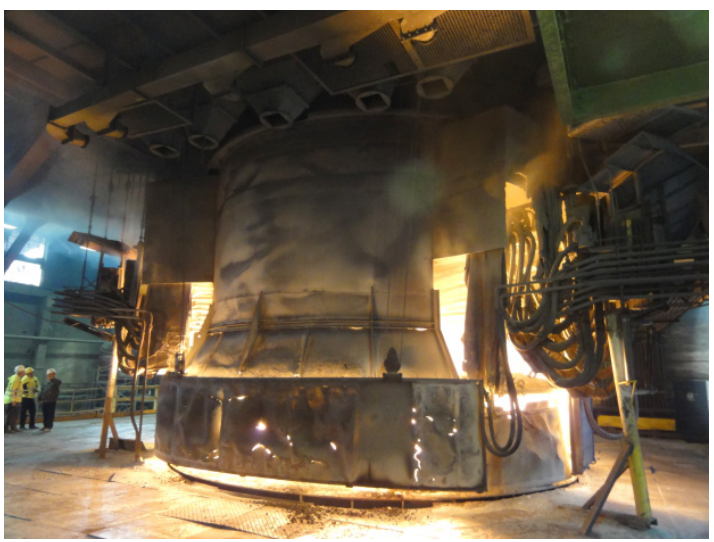

Fig. 2 ARC furnace used for ferroalloy production in OFZ, a.s. Istebne, plant Siroka

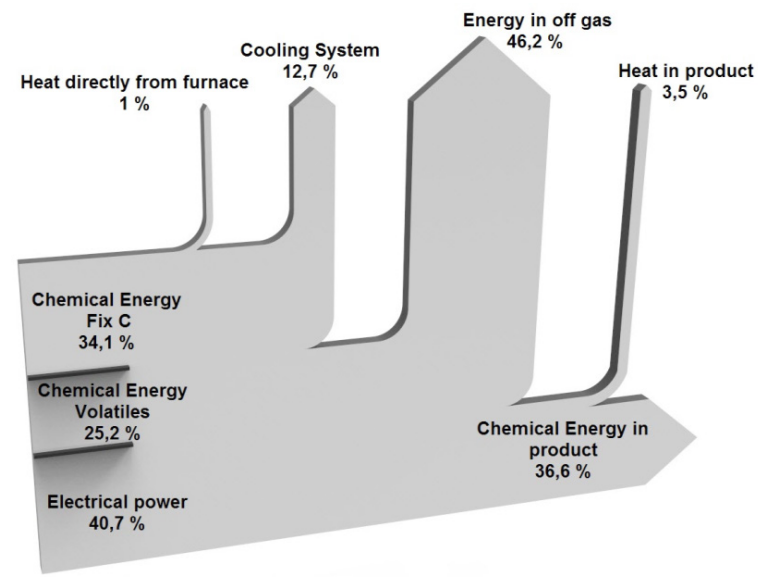

Fig. 3 A Sankey diagram of an electric arc furnace [2]

Ferroalloy furnaces work at relatively high temperatures. In ferrosilicon production the temperature of the furnace jacket is about $400^{\circ} \mathrm{C}$ and in the case of technological failures it achieves as much as $900-1000{ }^{\circ} \mathrm{C}$. When ferrosilicon is produced in electric arc furnaces (EAF) there are silicon ashes which are formed by condensation of silicon dioxide vapour radiating from the EAF. Ashes are very fine particles of regular spherical shape and smooth surface. Silicon ash is adhesive, features excellent heat insulating properties and increases heat resistance on the inner wall of the furnace roof.

The main task of the cooled roof is to carry away part of radiation and convection heat from the process of ferroalloy melting (Fig. 3) and recover it through the recovery equipment to the energy system of a company. Subsidiary effect of the equipment is to reduce the temperature of flue gases and to improve the workplace (reduction of average radiation temperature) in the vicinity of the furnace.

The roof is an auxiliary technological device suspended above the furnace on the manufacturing hall construction. It is of rotary shape with a perpendicular axis. There are three perpendicular electrodes installed in an axis of the furnace and roof. Current for the electrodes is supplied from three sides through holes in the roof.

\section{Numerical model of heat transport in the electric arc furnace}

To determine heat flows to individual parts of the EAF roof and, consequently, dimension the primary circuits of heat transfer medium, it was necessary to develop a numerical model of heat transport from melting charge and from flue gases to the heat exchanger walls positioned in the furnace roof. Numerical simulation of transfers in EAF in a stationary regime was performed in ANSYS Fluent 16.2 code taking into consideration a radiation element of heat transport.

3D geometry of an EAF simplified model was created in the program DesignModeler R16.2. The modelled system consists of four types of flue gas/water heat exchangers placed one above the other in four zones, of three electrodes and a part of flue gas removal without heat transfer surfaces. The total volume of an EAF simplified model was considered as fluid.

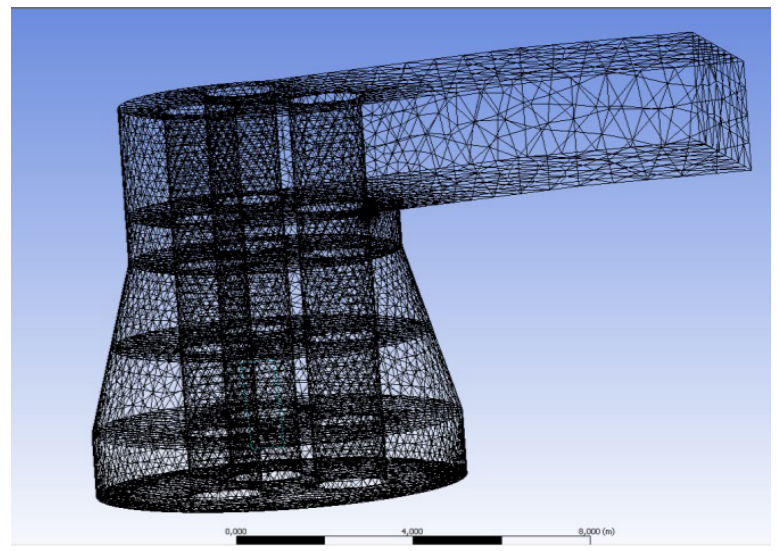

Fig. 4 Mesh generated in program Meshing R16.2

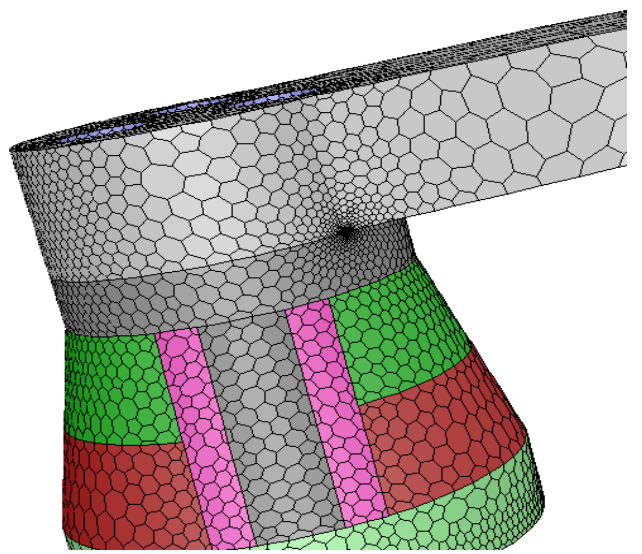

Fig. 5 Converted to polyhedral mesh 
Computer mesh for 3D simplified model of EAF was developed in the program Meshing R16.2 (Fig. 4). The mesh itself contains 332,564 cells. The mesh was built with the patch conforming method by means of which the cells of tetrahedron type were developed (Fig. 5) using the Patch Conforming algorithm. Advanced meshing functions Curvature and Proximity were used for meshing.

The achieved quality of mesh - skewness was 0.84 ; from the point of view of mesh assessment, this mesh is in the range of acceptability. To improve it and to speed up the numerical simulation, the mesh was further arranged through conversion to polyhedral mesh. This polyhedral mesh achieved the mesh quality - skewness of 0.75 and is assessed as good. This arrangement contributed to a faster conversion of the task.

In the numerical simulation, we chose the turbulence model $\mathrm{k}-\varepsilon$ with setting "realisable" that shows very good results in solving similar tasks [3,4 and 5]. To solve the radiation we used a radiation model Ordinates (DO) with resolution $5 \times 5$. In the equation for radiation transfer (1) [6], this model solves radiation intensity which depends on location and direction. Radiation heat transfer is counted in every quadrant or octant. It solves transport equations in a similar manner as when solving convection and energy balance according to:

$$
\begin{aligned}
& \nabla \cdot[I(\mathbf{r}, \mathbf{s}) \cdot \mathbf{s}]+\left(a+\sigma_{s}\right) I(\mathbf{r}, \mathbf{s})= \\
& a n^{2} \frac{\sigma T^{4}}{\pi}+\frac{\sigma_{s}}{4 \pi} \int_{0}^{4 \pi} I\left(\mathbf{r}, \mathbf{s}^{\prime}\right) \Phi\left(\mathbf{s} \cdot \mathbf{s}^{\prime}\right) d \mathbf{\Omega}^{\prime},
\end{aligned}
$$

\section{where}

$\mathbf{r}$ - position vector

$\mathbf{s}$ - directional vector

$\mathbf{s}^{\prime}$ - directional dispersion vector

$s$ - distance

$a$ - absorption coefficient

$n$ - refractive index

$\sigma_{s}$-coefficient of dispersion

$\sigma$ - Stefan-Boltzmann constant $\left(5.669 \times 10^{-8} \mathrm{Wm}^{-2} \mathrm{~K}^{-4}\right)$

$I$ - intensity of radiation which depends on position and direction

$T$ - local temperature

$\Phi$ - phase function

$\Omega^{\prime}$ - angle.
The simulation itself was performed in the program ANSYS Fluent 16.2. in which the boundary conditions were set according to Table 1 . Flue gases with a defined composition were taken as a working medium. Walls (wall - Table 1) of the model were developed as simplified and in simulation the number of layers, their thickness, temperature and emissivity were given (Fig. 6).

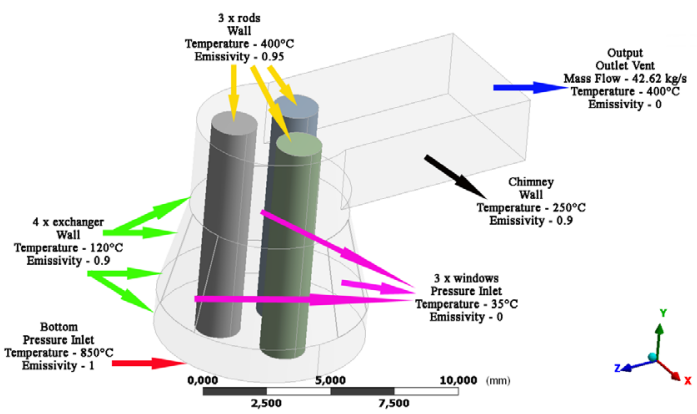

Fig. 6 Input parameters for a simulation model of EAF

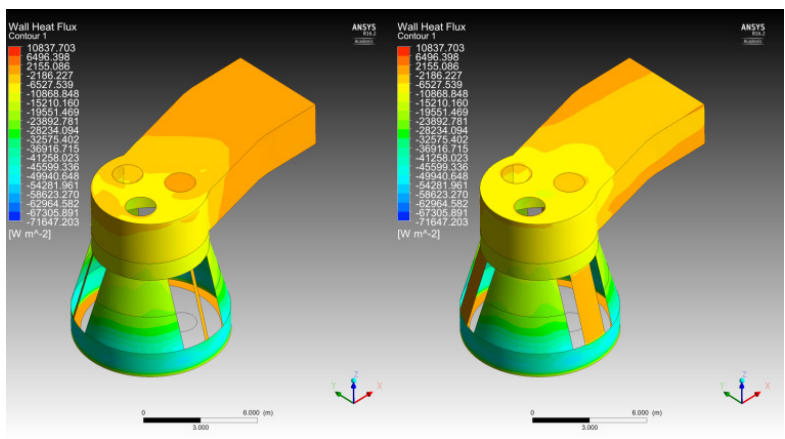

Fig. 7 Comparison of influence of the size of short mesh hole on the air intake and jacket temperature

The numerical simulation was performed in standard operational conditions with a stationary heat transport by radiation from the melting layer under chosen input parameters presented in Table 1. The change of input cross-section to the EAF roof through a hole for a short mesh was determined through the reduction of its cross-section according to the number and crosssections of cables and cooling pipes (Fig. 7). For the modelling of the hole for a short mesh we restricted the diameter of the hole

Boundary conditions

\begin{tabular}{|c|c|c|c|c|}
\hline \multirow[t]{2}{*}{ Name of boundary } & Input parameters & Mass flow & Temperature & Emissivity \\
\hline & Type of boundary & $\mathrm{kg} / \mathrm{s}$ & ${ }^{\circ} \mathrm{C}$ & \\
\hline bottom & pressure-inlet & - & 850 & 1 \\
\hline $3 \mathrm{x}$ windows & pressure-inlet & - & 35 & 0 \\
\hline output & outlet-vent & 42.62 & 400 & 0 \\
\hline $4 \times$ exchangers & wall & - & 120 & 0.9 \\
\hline chimney & wall & - & 250 & 0.9 \\
\hline $3 \times$ rods & wall & - & 400 & 0.95 \\
\hline
\end{tabular}

Table 1 
with a continuous band covering $50 \%$ of the input cross section among roof segments. The influence of the hole size on the volume flow of intake air and, thus also on the temperature of the jacket of flue gas removal unit can be seen in Fig. 7.
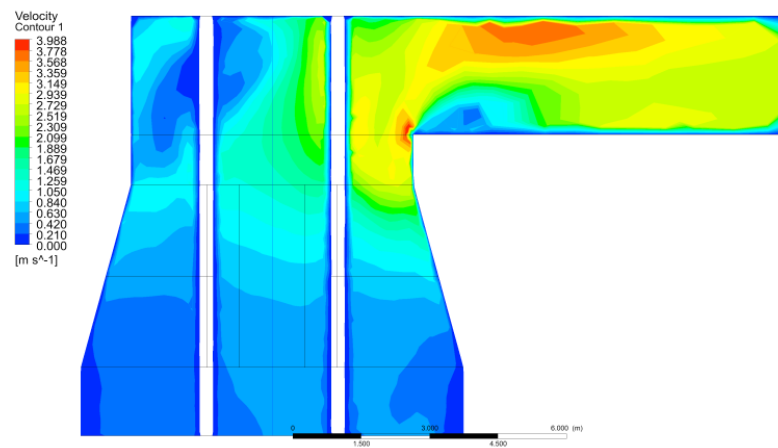

Fig. 8 Velocity field in a longitudinal section of flue gas removal unit

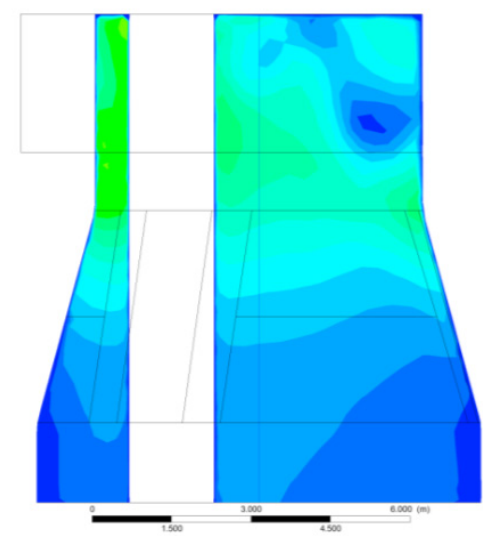

Fig. 9 Velocity field in vertical section to flue gas removal unit
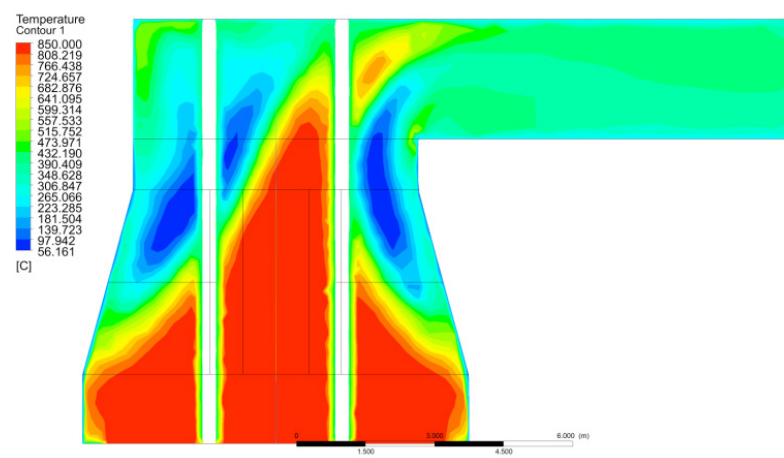

Fig. 10 Thermal field in a longitudinal section against flue gas removal unit

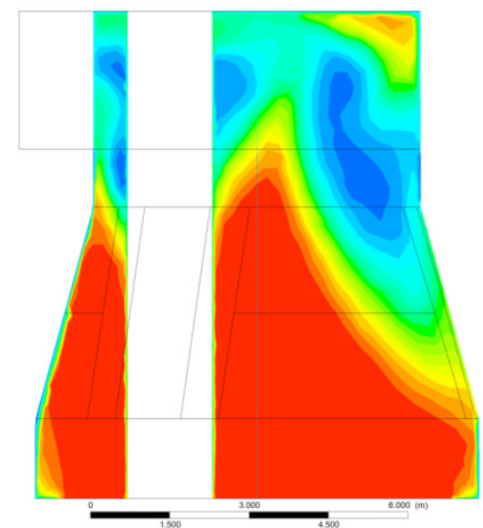

Fig. 11 Thermal field in vertical section to the axis of flue gas removal unit
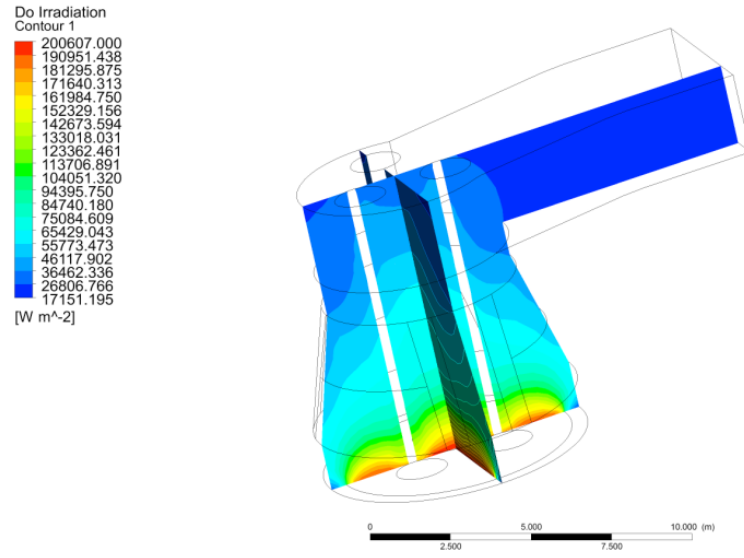

Fig. 12 Radiation density shown in two mutually perpendicular planes

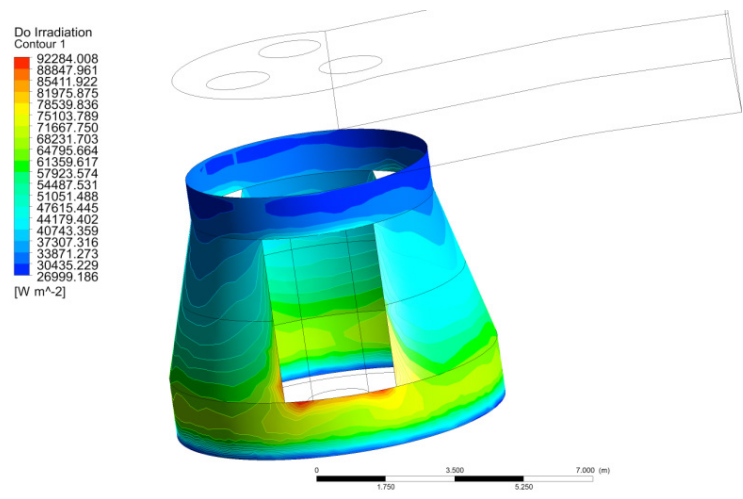

Fig. 13 Radiation flow to the roof wall

The result of simulation (Figs. 8, 9, 10, 11, 12 and 13) is the computation of radiation and convection element of heat transport to the four zones of the EAF roof (Fig. 12, 13 and 14). 


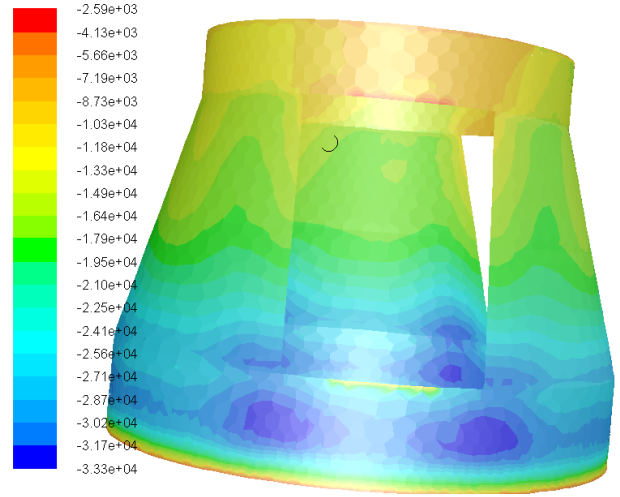

Fig. 14 The overall heat flow to the furnace roof through radiation and convection

The first zone comprises a cylindrical surface on which heat exchangers are placed marked as lifting screens and heat exchangers below the short mesh;

The second zone consists of heat exchangers in the bottom tapered part of the roof;

The third zone consists of heat exchangers in the upper tapered part of the roof;

The fourth zone consists of heat exchangers on the cylinder ring in the upper part of the EAF roof.

The computed mean weighted overall density of heat flow to individual zones which are free from flue ash is then as presented in Table 2.

Heat flow densities and thermal output of individual zones of EAF roof

Table 2

\begin{tabular}{|c|c|c|}
\hline Part of EAF roof & $\begin{array}{c}\text { Average density of } \\
\text { heat flow in a zone } \\
\left(\mathrm{kW} / \mathrm{m}^{2}\right)\end{array}$ & $\begin{array}{c}\text { Calculated overall } \\
\text { heat flow to the zones } \\
(\mathrm{kW})\end{array}$ \\
\hline $1^{\text {st }}$ zone & $\mathbf{2 6 . 6 8 4}$ & $\mathbf{1 0 5 5 . 7 0 6}$ \\
\hline $2^{\text {nd }}$ zone & $\mathbf{2 2 . 8 7 3}$ & $\mathbf{7 5 2 . 1 0 9}$ \\
\hline $3^{\text {rd }}$ zone & $\mathbf{1 6 . 1 1 9}$ & $\mathbf{4 1 2 . 0 5 2}$ \\
\hline $4^{\text {th }}$ zone & $\mathbf{1 1 . 5 5 7}$ & $\mathbf{2 4 7 . 3 8 3}$ \\
\hline
\end{tabular}

The simulations of heat transport in the EAF via a simplified geometry of an unobstructed furnace jacket showed that it is possible, after having implemented the proposed arrangements, to carry off the total thermal output of about $2.467 \mathrm{MW}$ from the EAF furnace roof to the heat transfer medium (warm water). Heat exchangers under a short mesh and those on the lifting screens seem to be the most powerful.

\section{Constructional solution of the heat recovery system}

When designing heat exchangers, attention is paid to the following facts so that they would:

- absorb mostly the radiation component of heat which prevails in the roof area,

- enable creating the largest possible area exposed to radiation and capturing the most possible amount of radiated heat [7],

- avoid reduction of the roof space and enable free flow of flue gases via the roof to the removal unit,

- have simple shapes without edges and corners, if possible, to avoid dust capturing,

- provide continuous functioning and technological process in the furnace,

- be resistant against failures, be controllable and repairable,

- be simple from production and material points of view.

The ring is the vital part of the cooled furnace roof. It is a welded construction from steel sheets and rolled profiles. The cooler segments are screwed to the lower flange of the ring and the flue removal unit is welded to the upper edge. On the ring periphery there are plate heat exchangers.

In order to achieve the required thermal output of about 2.5 MW it was necessary to add heat transfer surfaces to all usable surface of the furnace roof.

On the basis of calculated heat flows, we dimensioned pipes [8], heat exchangers and tube-type construction and developed a $3 \mathrm{D}$ model of the overall assembly of the EAF cooled roof.

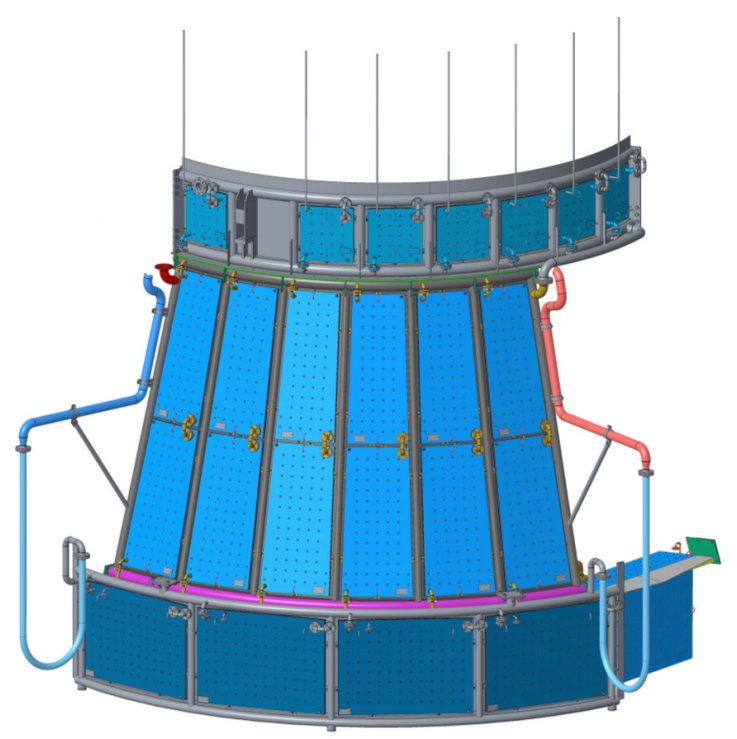

Fig. 15 A segment of pressure vessel of the EAF cooled roof

The furnace roof is designed as a pressure vessel divided into three independent segments (Fig. 15, 16 and 17). The segments consist of a set of plate heat exchangers and tube-type 
construction. Each segment is an independent unit of pressure vessels with a maximum pressure of $0.2 \mathrm{MPa}$ and maximum temperature of $110^{\circ} \mathrm{C}$.

Useful thermal output demand at the furnace performance of $18 \mathrm{MW}_{\mathrm{e}}$ is $2-2.5 \mathrm{MW}_{\mathrm{t}}$. This heat is recovered from waste heat originating during ferrosilicon production and is led to a heat exchanger station and, consequently used to heat water in a company. In the heat exchange station water in the heating circuit of a plant is heated to the temperature of max. $90^{\circ} \mathrm{C}$. When the heat from EAF roof is not usable for heating system, its degradation is provided in the cooling circuit of the company by means of individual heat exchangers placed in the heat exchanger station. The complete system of measurement, control and management is provided by the computer.

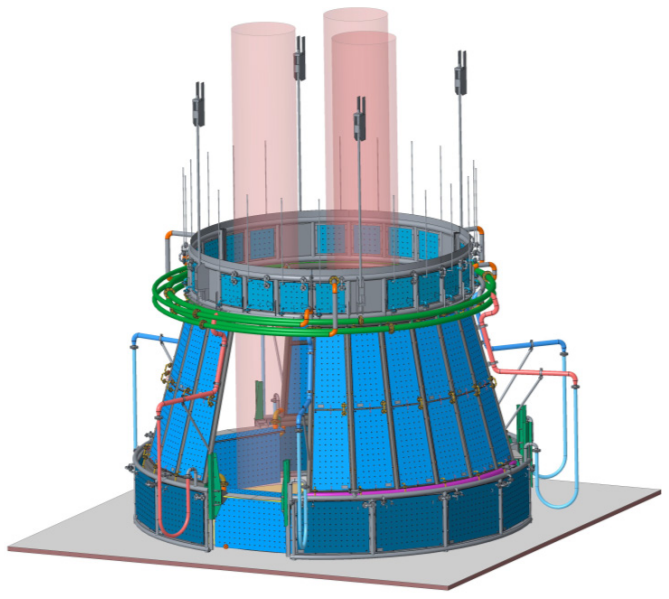

Fig. 16 The overall 3D model

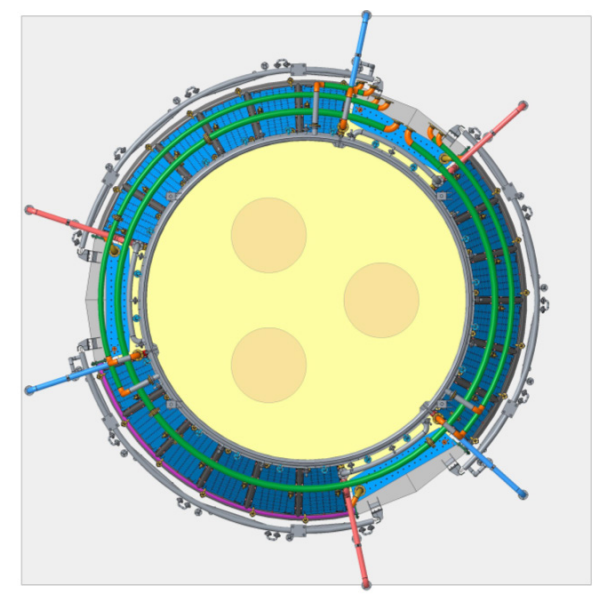

Fig. 17 Overall 3D model - plan view

\section{Conclusion}

The analysis of recovery of heat from electric arc furnaces showed that it is not a trivial problem. On the contrary, it requires a certain degree of experience from the field of recovery of heat from technological processes. Its solution should have a complex access not only to ways and forms of heat acquisition but also to possibilities of its utilisation. Highly efficient tools seem to be extensive program packages (code Ansys Fluent, ProEngineering), which enable - with the help of powerful computers - to analyse states also in such complicated thermal systems as electric arc furnaces are. Present experience also showed that it is necessary to design such technical solutions which accept the most relevant problem of heat recovery from EAF - clogging of heat transfer surfaces of recuperation exchangers by flue ash featuring very specific characteristic (perfect adhesion to uneven surfaces). The mentioned characteristic significantly impairs the use of waste heat from EAF for production of electric energy either by means of water vapour or ORC cycle. Current equipment requires a stable stationary relatively clean source of heat of high potential.

Great attention should be also paid to the high quality of control of the equipment designed for heat recovery which has to flexibly react to a non-stationary character of thermal loading of heat exchangers on the furnace roof resulting from a manner of clogging or from melting the surface of charge in the furnace.

Last but not least, there is a question of using considerable thermal benefits from hot water. This type of heat energy should, first of all, cover the requirements for heating (both of spaces and water). It is necessary to find such an auxiliary technology of waste heat utilisation which will provide optimal effect from invested means.

\section{Acknowledgements}

This paper has been elaborated in the framework of the project APVV-0577-10 Cooling of power electronic systems by cooling cycles without mechanical drive (COPES).

This contribution is the result of the project implementation: Slovak Infrastructure for High Performance Computing, ITMS code 26230120002, supported by the Research \& Development Operational Programme funded by the ERDF.

\section{References}

[1] KADKhODABEIGI, M., TVEIT, H., JOHANSEN, S. T.: Modeling the Tapping of Silicon Melt from the Submerged Arc Furnaces, $9^{\text {th }}$ Intern. Conference on CFD in the Minerals and Process Industries, CSIRO, Melbourne, 2009. 
[2] HJARTARSON, H., PALSSON, H., SAEVARSDOTTIR, G.: Waste Heat Utilization from a Submerged Arc Furnace Producing Ferrosilicon. 12 ${ }^{\text {th }}$ Intern. Ferroalloys Congress Sustainable Future, Helsinki, Finland 2010.

[3] LAZIC, L., VARGA, A., KIZEK, J.: Analysis of Combustion Characteristics in a Aluminium Melting Furnace. Metalurgija, vol. 44, pp. 195-199, 2005.

[4] MALCHO, M., JANDACKA, J. OCHODEK, T., KOLONICNY, J.: Correlations for Heat Transport by Natural Convection of Cylindrical Surfaces Situated Above the Other. Communication - Scientific Letters of the University of Zilina, vol. 17, No. 3, pp. 4-11, 2015.

[5] KAPJOR, A. HUZVAR, J., FTOREK, B., SMATANOVA, H.: Analysis of the Heat Transfer from Horizontal Pipes at Natural Convection, proc. of the intern conference XIX Application of experimental and numerical methods in fluid mechanics and energetics 2014, Melville : AIP Publishing, pp. 58-622014. ISBN 978-0-7354-1244-6.

[6] INCROPERA, F. P., DEWITT, D. P, BERGMAN, T. L, LAVINE, A. S.: Fundamentals of Heat and Mass Transfer, 6st ed. : John Wiley : New York, 2007.

[7] BRESTOVIC, T., CARNOGURSKA, M. PYSZKO, R., KUBIK, M. : Effect of Radiation on Heat Exchange in Finned Heat Transfer Surfaces, XVIII Intern. scientific conference The application of experimental and numerical methods in fluid mechanics and energy. EDIS: University of Zilina, 2012, pp. 19-26. ISBN 978-80-554-0516-2.

[8] SKOCILASOVA, B., SKOCILAS, J.: Determination of Pressure Drop Coefficient by CFD Simulation. Proc. of AIP Conference, vol. 1608, pp. 206-210, 2014.

\section{Uncited references or further readings}

[9] KAPJOR, A., GRESSAK, T., HUZVAR, J., VANTUCH, M.: Heat Transfer by Thermovision and CFD Methods. Proc. of AIP Conference, vol. 1608, pp. 103-107, 2014.

[10] KNOUREK, J., MATAS, R., PROKES, O., TENKRAT, D.: Numerical Simulations of Natural Gas Flow in Pipe System with Flowmeters. EPJ Web of Conferences, vol. 67, 2013. 